\title{
A serological survey of antibodies to Leptospira species in dogs in South Africa
}

\author{
J M Roach $^{\mathrm{a}, \mathrm{b}^{*}}$, M van Vuuren $^{\mathrm{a}}$ and J A Picard ${ }^{\mathrm{a}}$
}

\begin{abstract}
Leptospirosis, a disease more common in the tropics, can cause a life-threatening multisystemic syndrome in humans and animals. Immunity, whether natural or vaccineinduced, is serogroup-specific with the infecting serovars varying according to geographical locality. In South Africa, in spite of the fact that the bacterin vaccine for some Leptospira serovars is often used, there is no recent information on the incidence of canine leptospirosis as well as the infecting serovar/s. The aim of this study, which was undertaken on sera collected in 2008 and 2009 from both strays and owned dogs predominantly in the coastal regions of South Africa, was to determine the presence of leptospiral antibodies to 15 serovars known to infect dogs. Of the 530 samples tested, 25 tested positive to 7 different serovars with the microscopic agglutination test (MAT). Nine of the 25 samples tested positive to more than one serovar. The 2 serovars most frequently represented were Canicola, which reacted to 17 sera, and Pyrogenes, which reacted to 10 sera. Currently the only vaccines available in South Africa in different combinations contain serovars Canicola, Icterohaemorrhagiae, Pomona and Grippotyphosa. The results showed that the use of vaccines containing serovar Canicola is still justifiable in certain regions of the country. However, the presence of antibodies to serovar Pyrogenes in several dogs, pending a broader investigation, indicates that this serovar should also be included in the range of Leptospira vaccines for use in South Africa.
\end{abstract}

Keywords: dogs, Leptospira serovars, microscopic agglutination test, South Africa, vaccine. Roach J M, van Vuuren M, Picard J A A serological survey of antibodies to Leptospira species in dogs in South Africa. Journal of the South African Veterinary Association (2010) 81(3): 156-159 (En.). Department of Veterinary Tropical Diseases, Faculty of Veterinary Science, University of Pretoria, Private Bag X04, Onderstepoort, 0110 South Africa.

\section{INTRODUCTION}

Clinical cases of canine leptospirosis have historically been associated with Leptospira serovar Icterohaemorrhagiae, where rats act as the primary reservoir host and serovar Canicola where dogs are the maintenance host. In recent years the decrease in prevalence of these serovars in many 1st-world countries has been ascribed to widespread vaccination since the 1960s with homologous serovars ${ }^{7}$. A concomitant increase in other serovars, which is associated with the geographical region, is suggested to be the result of the encroachment of dogs into the environment of wildlife reservoir hosts of other serovars ${ }^{7}$

The 1st published report documenting the presence of leptospirosis in dogs in Cape Town, South Africa was published

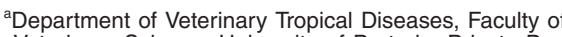
Veterinary Science, University of Pretoria, Private Bag X04, Onderstepoort, 0110 South Africa.

${ }^{b}$ Midlands Veterinary Clinic, 103a Main Street, Howick, 3290 South Africa.

*Author for correspondence.

E-mail: moritz.vanvuuren@up.ac.za

Received: June 2010. Accepted: July 2010 in 1953 where serovars Canicola and Sejroe were implicated ${ }^{13}$. In 1965, in Cape Town, sera of 100 dogs from a mostly impoverished community were tested for antibodies to Leptospira species. Of these, 43 had positive titres to serovar Canicola or serovar Icterohaemorrhagiae or both ${ }^{3}$. A later study evaluated the prevalence of leptospirosis in dogs in the Pretoria area in 1993. Sera collected from stray dogs were tested for serovars Canicola, Copenhageni, Grippotyphosa, Hardjo, Mini, Pomona, Pyrogenes and Tarassovi. Only $1.5 \%$ of dogs tested had antibodies to serovars Tarassovi and Pyrogenes. It was suggested that leptospirosis is not of clinical significance in the Pretoria area, possibly as a result of the dry climate ${ }^{17}$. In 1973, a report of serovar Canicola causing illness and death in dogs and abortions in pigs in the Stellenbosch district was published ${ }^{22}$. There are also reports of leptospirosis affecting pigs, cattle and wild animals in South Africa ${ }^{8,10,15,16,19,21}$. A recent study conducted on cattle from rural communities in KwaZulu-Natal identified Pomona as the most common serovar although serovars Tarassovi, Bratislava, Hardjo, Canicola and Icterohaemorrhagiae were also identified ${ }^{9}$.

Even though veterinary practitioners in the subtropical coastal areas of South Africa have a perception that leptospirosis is present in dogs and immunise them against the disease, diagnoses of leptospirosis are lacking. It was the aim of this study to collect sera from healthy dogs to determine whether antibodies to any of the 15 different serovars could be demonstrated.

\section{MATERIALS AND METHODS}

Clotted blood samples were collected by branches of the Society for Prevention of Cruelty to Animals (SPCA) and various private practices. The samples from the SPCAs were collected, just prior to euthanasia, from healthy stray dogs with unknown vaccination and medical histories. Samples from private practices were collected from dogs presented for routine checks, pre-anaesthetic profiles or for ill health. Every attempt was made to bleed unvaccinated dogs but in some cases the vaccination histories of the dogs were unavailable. Estimating the expected disease prevalence to be $5 \%$ and utilising a confidence interval of $95 \%$ and precision of $\mathrm{P} / 2$ i.e. 0.0025 a sample size of 219.84 was calculated (Epi Info ${ }^{\mathrm{TM}} 3.5 .1$ ). Allowing for incomplete data in some of the samples it was elected to over-sample by at least $100 \%$. It was therefore decided to collect at least 440 blood samples.

Live leptospiral organisms representing 15 serovars and 11 serogroups (Table 1) were imported from the Royal Tropical Institute (KIT Biomedical Research Laboratory) in Amsterdam, the Netherlands.

They were maintained at $29^{\circ} \mathrm{C}$ in DifcoTM Leptospira Enrichment EMJH broth and subcultured in $5 \mathrm{~m} \ell$ quantities at 7-day intervals until required. The viability and purity of the cultures were checked by dark-field microscopy. Cultures were used for the serological tests between the 4th and 10th day of growth of that culture cycle ${ }^{4}$.

Serum samples were identified and numbered and the data (i.e. sex, age, breed and geographical region) pertaining 
to each recorded. Sera were frozen and stored prior to testing. The Microscopic Agglutination Test (MAT) was carried out as described in the Office International des Épizooties (OIE) Manual of Diagnostic Tests and Vaccines for Terrestrial Ani mals ${ }^{18}$ using a 1:50 dilution of sera. All those sera showing agglutination underwent further 10-fold dilutions in a range of 1:100 to $1: 6400$ and were tested using serovars to which they had shown agglutination. The antibody titre was taken as the highest dilution where $50 \%$ agglutination was recorded compared with a negative control. A titre of $\geq 1: 100$ was accepted as evidence of past exposure to leptospires.

\section{RESULTS}

In total 530 sera were collected from the KwaZulu-Natal, Eastern Cape, Western Cape and Gauteng regions, where 25 sera revealed antibodies to one or more serovars i.e. $4.7 \%$ of the total number tested (Table 2).

It was found that dogs from the Eastern

Table 1: The organisms used as capture antigens in the MAT represent 11 different serogroups.

\begin{tabular}{|c|c|}
\hline Serogroup & Serovar \\
\hline Australis & $\begin{array}{l}\text { L. interrogans serovar Australis strain Ballico } \\
\text { L. interrogans serovar Australis strain Ballico var Bratislava jez Bratislava }\end{array}$ \\
\hline Autumnalis & L. interrogans serovar Autumnalis strain Akiyami A. \\
\hline Bataviae & L. interrogans serovar Bataviae strain Swart. \\
\hline Canicola & L. interrogans serovar Canicola strain Hond Utrecht IV. \\
\hline Grippotyphosa & L. kirschneri serovar Grippotyphosa strain Moskva V. \\
\hline Icterohaemorrhagiae & $\begin{array}{l}\text { L. interrogans serovar Copenhageni strain M20 } \\
\text { L. interrogans serovar Icterohaemorrhagiae strain RGA. }\end{array}$ \\
\hline Mini & L. interrogans serovar Szwajizak strain Szwajizak. \\
\hline Pomona & L. interrogans serovar Pomona strain Pomona. \\
\hline Pyrogenes & L. interrogans serovar Pyrogenes strain Salinem. \\
\hline Sejroe & $\begin{array}{l}\text { L. interrogans serovar Hardjo strain Hardjoprajitno, } \\
\text { L. interrogans serovar Wolfii strain } 3705 \\
\text { L. borgpetersenii serovar Sejroe strain M84. }\end{array}$ \\
\hline Tarassovi & L. borgpetersenii serovar Tarassovi strain Perepelitsin. \\
\hline
\end{tabular}

Cape $(P=0.02)$ followed by KwaZuluNatal $(P=0.02)$ were more likely to have leptospiral antibodies than dogs from the Western Cape. As a consequence of the small number of samples from Gauteng, an inland province, no statistically significant differences were noted when the other provinces were compared with this one (Table 3).

At a confidence level of $95 \%$, it was

Table 2: Profiles of the dogs that were seropositive with the MAT.

\begin{tabular}{|c|c|c|c|c|c|}
\hline Age & Breed & Sex & Area & Serovar & Titre \\
\hline \multicolumn{6}{|c|}{ KwaZulu-Natal } \\
\hline \multirow[t]{3}{*}{ Adult } & Cross-breed & M & Kloof & Icterohaemorrhagiae & 800 \\
\hline & & & & Copenhageni & 400 \\
\hline & & & & Bratislava & 200 \\
\hline \multirow[t]{2}{*}{ Adult } & Staffordshire bull terrier & M & Pinetown & Bratislava & 200 \\
\hline & & & & Pyrogenes & 400 \\
\hline \multirow[t]{2}{*}{ Adult } & Cross-breed & $\mathrm{F}$ & Northdene & Pyrogenes & 100 \\
\hline & & & & Canicola & 400 \\
\hline \multirow[t]{3}{*}{ Adult } & Pug & M & Gillits & Pyrogenes & 200 \\
\hline & & & & Canicola & 200 \\
\hline & & & & Bataviae & 200 \\
\hline $6 \mathrm{yr}$ & German shepherd & M & Westville & Australis & 800 \\
\hline $2 \mathrm{yr}$ & Spaniel & $\mathrm{F}$ & Dundee & Canicola & 100 \\
\hline $3 \mathrm{yr}$ & Cross-breed & M & Pietermaritzburg & Canicola & 200 \\
\hline $9 \mathrm{yr}$ & Greyhound & $\mathrm{F}$ & Pietermaritzburg & Canicola & 100 \\
\hline $10 \mathrm{yr}$ & Fox terrier & $\mathrm{F}$ & Hilton & Canicola & 200 \\
\hline $5 \mathrm{yr}$ & German shepherd cross & M & Pietermaritzburg & Canicola & 400 \\
\hline \multirow[t]{2}{*}{$3 \mathrm{yr}$} & Cross-breed & $\mathrm{F}$ & Northdale & Canicola & 800 \\
\hline & & & & Icterohaemorrhagiae & 100 \\
\hline $5 \mathrm{yr}$ & Labrador & M & Pietermaritzburg & Canicola & 800 \\
\hline \multirow[t]{2}{*}{$2 y r$} & Cross-breed & M & Napierville & Canicola & 100 \\
\hline & & & & Pyrogenes & 100 \\
\hline \multicolumn{6}{|c|}{ Eastern Cape } \\
\hline $4 \mathrm{yr}$ & Cross-breed & M & Port Elizabeth & Canicola & 200 \\
\hline $1 \mathrm{yr}$ & Cross-breed & $\mathrm{F}$ & Port Elizabeth & Autumnalis & 400 \\
\hline $3 \mathrm{yr}$ & Cross-breed & $\mathrm{F}$ & Port Elizabeth & Pyrogenes & 200 \\
\hline $10 \mathrm{yr}$ & Cross-breed & M & Port Elizabeth & Pyrogenes & 100 \\
\hline \multirow{2}{*}{$3 \mathrm{yr}$} & Cross-breed & M & Port Elizabeth & Pyrogenes & 200 \\
\hline & & & & Canicola & 800 \\
\hline $4 \mathrm{yr}$ & Cross-breed & $\mathrm{F}$ & Port Elizabeth & Canicola & 800 \\
\hline Adult & Jack Russell & $\mathrm{F}$ & Humansdorp & Canicola & 1600 \\
\hline $6 \mathrm{~m}$ & Border collie & $\mathrm{F}$ & Humansdorp & Canicola & 200 \\
\hline \multicolumn{6}{|c|}{ Western Cape } \\
\hline $2 \mathrm{yr}$ & Cross-breed & M & Grassy Park & Pyrogenes & 200 \\
\hline $12 \mathrm{yr}$ & Cross-breed & $\mathrm{F}$ & Grassy Park & Canicola & 400 \\
\hline \multicolumn{6}{|l|}{ Gauteng } \\
\hline \multirow[t]{2}{*}{ Adult } & Sample 13 & Unknown & Gauteng & Canicola & 100 \\
\hline & & & & Pyrogenes & 100 \\
\hline \multirow[t]{2}{*}{$1.5 \mathrm{yr}$} & Africanus & $\mathrm{F}$ & Gauteng & Canicola & 1600 \\
\hline & & & & Pyrogenes & 400 \\
\hline
\end{tabular}


Table 3: A statistical comparison of the seroprevalance of Leptospira antibodies between provinces (Fisher's exact test).

\begin{tabular}{lcccc}
\hline Province & $\begin{array}{c}\text { Number of positive } \\
\text { animals/Total }\end{array}$ & KwaZulu-Natal & Eastern Cape & Western Cape \\
\hline KwaZulu-Natal & $13 / 255$ & & & \\
Eastern Cape & $8 / 55$ & 0.02 & & \\
Western Cape & $2 / 195$ & 0.02 & $<0.001$ & 0.31 \\
Gauteng & $1 / 25$ & 1.00 & 0.26 & \\
\hline
\end{tabular}

found that male (confidence interval (CI) $2.7,9.0)$ and female (CI 2.2, 7.1) animals were equally likely to have antibodies to Leptospira serovars $(P=0.68)$. This was true even when the sexual differences within provinces were examined (results not shown). Of the 25 positive dogs, 12 were cross-breeds. Using the Pearson $2 \times$ 2 chi-square test, it was found at a $95 \%$ confidence level that stray dogs were more 4.09 (risk ratio) times more likely to have leptospiral antibodies than owned dogs $(P=0.0017)$.

\section{DISCUSSION}

The aim of this project was to collect samples from dogs from various regions in the country, record the relevant data pertaining to each sample and test the samples for antibodies against a variety of Leptospira serovars. A sample bias was included in that coastal regions were over-represented due to the fact that leptospirosis is known to be more common in warm, wet areas such as are found along the South African coast ${ }^{14}$.

Clearly stray dogs were 4.347 times more likely $(P=0.0017)$ to have antibodies to Leptospira species. Although the vaccination status of these dogs was unknown, most of the dogs originated from informal settlements where there are no resources to vaccinate dogs. It is therefore most likely that the antibodies present are due to exposure to infection with Leptospira species. It is known that free-roaming dogs compared with dogs restricted to properties are more likely to come into contact with known sources of the bacterium, either by drinking or swimming in contaminated stagnant freshwater, by contact with rodents or rodent urine-contaminated foods, as well as unrestricted mating with possibly infected dogs. In a study in the USA it was found that dogs that developed leptospirosis had statistically significant higher odds of having swum in or drunk open water in the 2 weeks preceding their illness than those which did not become ill ${ }^{6}$. The fact that the canine serovar Canicola predominated in this study indicates that unrestricted mating or the close contact with urine aerosols from other dogs is the most likely method of transmission ${ }^{4}$.
Six of the 13 seropositive dogs from KwaZulu-Natal, all the seropositive dogs in the Western Cape and 6 of the 8 seropositive dogs in the Eastern Cape were cross-breeds. Other than the cross-breeds, no other breed predominated. It was thought that since the cross-breeds in the study were mainly strays, the fact that they were able to roam freely and were able to breed was more of a risk factor than the fact that there was a specific breed predilection.

There was no significant difference found in prevalence between the sexes in this study; however, in a retrospective study conducted in the USA between 1997 and 2000, male dogs were found to be at increased risk of leptospirosis than females $^{23}$. The same was true for Japan where twice as many male as female dogs had leptospiral antibodies ${ }^{20}$. In a study conducted in Australia, although there was a trend for more female dogs to be positive than male, it was not found to be statistically significant ${ }^{24}$. There appear, therefore, to be other risk factors that are specific to a particular region or country, i.e. the proportion of breeding animals in a dog population and whether dogs are able to roam freely.

Antibodies to serovar Canicola predominated and were identified in all the provinces tested. As this serovar is present in the vaccine, the possibility that immunisation responses were being detected must be considered. In South Africa, all the leptospiral bacterins for use in dogs contain both serovars Canicola and Icterohaemorrhagiae. One would therefore expect a similar number of positive reactors to both serovars if the titres were indeed vaccine-induced. With the exception of 1 owned dog, this was not the case. In this dog the antibody titre to serovar Canicola was high at 1:800, indicating that the antibody response to at least serovar Canicola was due to natural infection.

Serovar Pyrogenes was previously identified in dogs in South Africa by Myburgh et al. in $1993^{17}$ but was not a commonly identified serovar in other studies conducted in South Africa ${ }^{3,13,22}$. Similarly, in a survey conducted on 820 dogs in Japan over a 3-year period, the 3rd most common serovar to which anti- bodies was detected after Icterohaemorrhagiae (57 dogs) and Canicola (53 dogs) was Pyrogenes $(10 \mathrm{dogs})^{20}$. In Brazil, antibodies to this serovar were found in $12 \%$ of the dogs tested ${ }^{1}$. In the current survey, it does assume some importance as it was found in every region tested and was the 2nd most commonly identified serovar.

Of the 4 regions represented, 3 (i.e. Western and Eastern Cape and Gauteng) only had positives to serovars Canicola and Pyrogenes apart from 1 positive reactor to serovar Autumnalis in the Eastern Cape. By contrast, the dogs tested in KwaZulu Natal reacted to 7 different serovars including some not previously identified in South Africa. The climate in KwaZuluNatal, particularly in the coastal areas, is warm and wet and ideal for the environmental survival of the organism ${ }^{4}$.

Although it is well known that crossreactive antibodies occur within a serogroup, it is generally considered that this is less prevalent when serovars belong to different serogroups (Table 1$)^{11,12}$. Therefore the presence of antibodies to serovars Icterohaemorrhagiae and Copenhageni is most likely the result of a cross-reaction, with serovar Icterohaemorrhagiae being the most likely infecting serovar since it had the highest antibody titre. However, in most cases antibodies were found to different serogroups, the most common combination being serovars Canicola and Pyrogenes. This seems to imply that those dogs have been exposed to several serovars.

A number of studies relating to Leptospira antibodies in southern Africa in animals other than dogs have been published. Of the serovars identified in this study both Copenhageni and Bratislava have been identified previously in South Africa in production animals and serovar Copenhageni in wild animals ${ }^{8,9,10,19}$. Antibodies to serovars Batavia and Autumnalis have also been detected in game in Zimbabwe. In a serological and bacteriological study conducted on cattle in Zimbabwe all the serovars identified in the current survey, except Bratislava and Copenhageni, were identified $^{2,5}$. It is therefore feasible for free-ranging dogs which may at times be in the same habitat as livestock and wild animals to have been exposed to any of the Leptospira serovars found in southern Africa.

Results from this study confirmed that serovars Canicola and Icterohaemorrhagiae are still present in South Africa but there are other serovars that are not included in any of the current generation of canine vaccines available in South Africa. This may become a problem over time. These are (with the number of 
positive samples in brackets) serovars Pyrogenes (10), Bratislava (2), Batavia (1), Copenhageni (1), Australis (1) and Autumnalis (1). Serovar Pyrogenes was found in all of the provinces where samples were taken. Prior to this study, of the positive serovars, only Canicola, Icterohaemorrhagiae and Pyrogenes had been identified in dogs in South Africa.

Serovars Bratislava and Copenhageni had been identified in production animals and serovar Copenhageni in wild animals. Serovars Autumnalis, Australis and Bataviae although identified in cattle and game in southern Africa have not been reported in South Africa.

Although further surveys in other areas of the country, especially the inland Provinces, still need to be undertaken, the results from this study have shown that leptospirosis still represents a risk, albeit a moderate one, to domestic dogs. It is suggested that the use of Leptospira vaccines containing the serovars Canicola and Icterohaemorrhagiae should be continued particularly in the warm coastal regions of the country and for groups of dogs that are considered to be at risk. It is also motivated that serovar Pyrogenes be included in any new vaccines.

\section{ACKNOWLEDGEMENTS}

Funding for the project was provided by Pfizer Laboratories SA and is gratefully acknowledged. The authors wish to thank Johan Gouws of the Department of Veterinary Tropical Diseases, Faculty of Veterinary Science, Onderstepoort and Andrew Potts and Christine Lotter from the Onderstepoort Veterinary Institute, as well as the many private veterinarians and the staff at Idexx laboratories without whose help the project would not have been completed. Professor Peter Thompson is thanked for conducting the statistical analysis of the results.

\section{REFERENCES}

1. Aguiar D M, Cavalcante G T, Marvulo MF V, Silva J C R, Pinter A, Vasconcellos S A, Morais Z M, Labruna M B, Canargo L M A, Gennari S M 2007 Risk factors associated with anti-Leptospira spp antibodies occurrence in dogs from Monte Negro County, Rondônia, Brazilian Western Amazon. Arquivo Brasileiro de Medicina Veterinária e Zootecnia 59: 70-76

2. Anderson E C, Rowe L W 1998 The prevalence of antibody to the viruses of bovine virus diarrhea, bovine herpes 1 , rift valley fever, ephemeral fever and blue tongue and to Leptospira sp in free-ranging wildlife in Zimbabwe. Epidemiology and Infection 121: 441-449

3. Beyers C P B 1965 Serological and Cultural evidence of Leptospirae in Cape Town dogs. South African Medical Journal 39: 797-798

4. Faine S, Adler B, Bolin C, Perolat P 1999 Leptospira and leptospirosis (2nd edn). MediSci, Melbourne

5. Feresu S B 1990 Leptospirosis in cattle in Zimbabwe. Ambio: A Journal of the Human Environment 19: 394-396

6. Ghneim G S, Viers J H, Chomel B B, Kass P H, Descollonges D A, Johnson M L 2007 Use of a case-control study and geographic information systems to determine environmental and demographic risk factors for canine leptospirosis. Veterinary Research 38: 37-50

7. Greene C E 2003 Canine leptospirosis: a re-emerging disease. Proceedings of the 28th World Congress of the World Small Animal Veterinary Association, Bangkok, Thailand, 24-27 October 2003

8. Gummow B, Myburgh J G, Thompson P N, Van Der Lugt J J, Spencer B T 1999 Three case studies involving Leptospira interrogans serovar pomona infection in mixed farming units. Journal of the South African Veterinary Association 70: 29-34

9. Hesterberg U W, Bagnall R, Bosch B, Perrett K, Horner R., Gummow B 2009 A serological survey of leptospirosis in cattle of rural communities in the province of KwaZulu-Natal, South Africa. Journal of the South African Veterinary Association 80: 45-49

10. Hunter P, Flamand J R, Myburgh J, Van Der Merwe S M 1988 Serological reactions to Leptospira species in game animals of northern Natal. Onderstepoort Journal of Veterinary Research 55: 191-192

11. Levett P N 2001 Leptospirosis. Clinical Microbiology Reviews 14: 296-326
12. Levett P N 2003 Usefulness of serologic analysis as a predictor of the infecting serovar in patients with severe leptospirosis. Clinical Infectious Diseases 36: 447-452

13. Malherbe W D, Kaschula V R 1953 Leptospirosis in dogs in South Africa. Journal of the South African Veterinary Medical Association 24: 163-169

14. McDonough P L 2001 Recent advances in canine infectious diseases. Online at: http:// www.ivis.org. Document No. A0112.0701 (accessed 20 August 2007)

15. Myburgh J G, Bengis R G, Bester C J, Chaparro F 1990 Serological reactions to Leptospira species in buffalo (Syncerus caffer) from the Kruger National Park. Onderstepoort Journal of Veterinary Research 57: 281-282

16. Myburgh J G, Otto Q T 1990 Serological survey for bovine leptospirosis in the Volksrust district. Journal of the South African Veterinary Association 61: 172-173

17. Myburgh J G, Posnett S J, Lawrence J V 1993 Serological survey for canine leptospirosis in the Pretoria area. Journal of the South African Veterinary Association 64: 37-38

18. OIE 2008 Manual of diagnostic tests and vaccines for terrestrial animals. OIE (World Organisation for Animal Health), Paris

19. Potts A D, Lotter C, Robinson J T 1995 Serological prevalence of leptospiral antibodies in pigs in South Africa. Onderstepoort Journal of Veterinary Research 62: 281-284

20. Ryu E 1975 An investigation of canine antileptospiral antibodies in Japan. International Journal of Zoonoses 2: 16-34

21. Te Brugge L A, Dreyer T 1985 Leptospira interrogans serovar hardjo associated with bovine abortion in South Africa. Onderstepoort Journal of Veterinary Research 52: 51-52

22. Van Rensburg W J 1973 Isolation of Leptospira canicola in swine and dogs in South Africa. Journal of the South African Veterinary Association 44: 435-436

23. Ward M P, Guptill L F, Prahl A, Wu C C 2004 Serovar-specific prevalence and risk factors for leptospirosis among dogs: 90 cases (1997-2002). Journal of the American Veterinary Medical Association 224: 1958-1963

24. Zwijnenberg R G J, Smythe L D, Symonds M L, Dohnt, M F, Toribioj-Alml 2008 Crosssectional study of canine leptospirosis in animal shelter populations in mainland Australia. Australian Veterinary Journal 86: 317-323 